\title{
PERBEDAAN PEMAHAMAN KONSEP FISIKA PADA PENERAPAN MODEL PEMBELAJARAN GUIDED DISCOVERY BERBANTUAN KOMIK DAN TANPA BANTUAN KOMIK PADA SISWA KELAS VIII SMP AL-AZHAR MANDIRI PALU
}

\author{
Sofwiyatul Banat, Muslimin dan Sahrul Saehana \\ Jurusan Pendidikan MIPA \\ Fakultas Keguruan dan IImu Pendidikan Universitas Tadulako Palu
}

\begin{abstract}
Abstrak - Penelitian ini bertujuan untuk mengetahui perbedaan pemahaman konsep fisika antara kelas yang menggunakan model pembelajaran guided discovery berbantuan komik dengan kelas yang menggunakan model pembelajaran guided discovery tanpa bantuan komik pada siswa kelas VIII SMP AlAzhar Mandiri Palu. Penelitian ini tergolong penelitian Quasi Experimental dengan desain Non-Equivalent Control Group. Sampel penelitian ini adalah 47 siswa. Data pemahaman konsep dikumpulkan dengan memberikan tes pemahaman konsep yang terdiri dari 5 soal uraian. Uji hipotesis dilakukan dengan menggunakan uji dua pihak. Berdasarkan hasil uji hipotesis, diperoleh bahwa terdapat perbedaan pemahaman konsep fisika antara kelas yang menggunakan model pembelajaran guided discovery berbantuan komik dengan kelas yang menggunakan model pembelajaran guided discovery tanpa bantuan komik (nilai thitung $=4,35>$ nilai $t_{(1-0,5 \alpha)}=2,01$ ). Gain Score kedua kelas tersebut berada pada kriteria sedang. Oleh karena itu, dapat disimpulkan bahwa terdapat perbedaan pemahaman konsep fisika yang kurang signifikan antara kelas yang menggunakan model pembelajaran guided discovery berbantuan komik dengan kelas yang menggunakan model pembelajaran guided discovery tanpa bantuan komik pada siswa kelas VIII SMP Al-Azhar Mandiri Palu.
\end{abstract}

Kata Kunci:pemahaman konsep fisika, model pembelajaran guided discovery, komik

\section{PENDAHULUAN}

Fisika adalah salah satu cabang ilmu pengetahuan alam yang menjelaskan mengenai gejala-gejala di alam dari segi fisis, dan membawanya ke dalam perumusan matematis. Fisika menguraikan sejumlah konsep dari gejalagejala di alam yang dekat dengan kehidupan manusia. Salah satu permasalahan yang dihadapi siswa dalam belajar fisika adalah kesulitan dalam memahami konsep yang sifatnya masih abstrak, sehingga membutuhkan imajinasi untuk memahaminya.

Berdasarkan informasi yang diperoleh dari guru, tingkat pemahaman konsep fisika siswa di SMP Al-Azhar Mandiri Palu dalam kategori sedang. Hal ini ditunjukkan dengan nilai rata-rata Ujian Akhir Semester (UAS) ganjil mata pelajaran fisika dari tiga kelas yang diajarkan oleh guru tersebut pada tahun ajaran $2017 / 2018$ yaitu 63,64 . Nilai tersebut masih di bawah KKM (Kriteria Ketuntasan Minimum) dan menggambarkan tingkat pemahaman konsep siswa SMP Al-Azhar Mandiri Palu masih dalam kategori sedang. Guru menuturkan bahwa siswa lebih unggul dalam mengerjakan soal perhitungan dibandingkan soal pemahaman konsep. Padahal, pembelajaran fisika seharusnya lebih menekankan pada pemahaman konsep. Menurut Pramadi, dkk pemahaman menjadi pondasi kemampuankemampuan yang lebih tinggi [1]. Pembelajaran akan lebih bermakna apabila siswa diarahkan untuk memahami konsep, karena siswa akan mengetahui manfaat dari materi fisika yang dipelajari dalam kehidupannya.
Melihat permasalahan tersebut, diperlukan suatu model pembelajaran yang dapat membantu siswa memahami konsep fisika. Selain itu, perlu digunakan juga suatu media untuk memperjelas penyajian pesan (dalam hal ini materi fisika) agar tidak terlalu bersifat verbalistis (dalam bentuk kata-kata tertulis atau lisan belaka) sehingga memudahkan siswa dalam memahami konsep fisika.

Salah satu model pembelajaran yang dapat diterapkan untuk mengajarkan konsep fisika adalah guided discovery. Menurut Yurahly model guided discovery (penemuan terbimbing) mendorong siswa untuk berpikir sendiri sehingga dapat menemukan prinsip umum yang diinginkan dengan bimbingan dan petunjuk dari guru [2]. Zulhelmi (dalam ref. [2]) menuturkan bahwa pembelajaran guided discovery memberikan peluang bagi aktivitas kelas yang berpusat pada siswa dan memungkinkan siswa belajar dengan memanfaatkan berbagai sumber belajar dan tidak menjadikan guru sebagai satu-satunya sumber belajar. Carin dan Sund(dalam Ref. [3]) menyatakan bahwa salah satu keuntungan pembelajaran dengan menggunakan pendekatan guided discovery adalah materi yang dipelajari lebih lama membekas karena siswa dilibatkan dalam proses menemukannya

Guided discovery telah digunakan sebagai model pembelajaran di SMP Al-Azhar Mandiri Palu. Guru menuturkan bahwa model ini mampu mendorong siswa untuk terlibat aktif dalam pembelajaran. Melalui model ini, siswa diajak untuk melakukan penemuan yang melibatkan siswa secara langsung. Melalui penggunaan model ini, tingkat pemahaman konsep fisika siswa 
pada kategori sedang. Inovasi yang dilakukan dengan mengkombinasikan model guided discovery dengan suatu media pembelajaran yang dapat memvisualisasikan konsep fisika yang masih abstrak, diharapkan dapat membantu siswa lebih memahami konsep fisika.

Sakti, dkk mengungkapkan bahwa media pendidikan adalah media yang penggunaannya diintegrasikan dengan tujuan dan isi pengajaran dan dimaksudkan untuk mempertinggi mutu mengajar dan belajar [4]. Pemakaian media pengajaran dalam proses pembelajaran dapat membangkitkan keinginan dan minat yang baru, membangkitkan motivasi dan rangsangan kegiatan belajar, serta membawa pengaruh psikologi terhadap siswa. Hal lain yang penting dari penggunaan media ini adalah untuk memperjelas penyajian pesan dan mengatasi keterbatasan daya indera.

Media untuk menggambarkan konsep fisika termasuk jenis media visual. Salah satu bentuk media visual tersebut adalah komik. Menurut Shadely (dalam Pramadi dkk) komik merupakan media yang berbentuk gambar, yang disusun dalam kotak yang keseluruhannya merupakan rentetan suatu cerita [1]. Penggunaan media komik dapat memvisualisasikan konsep fisika sehingga dapat membantu siswa memahami konsep fisika yang dipelajari. Tatalovic menyatakan bahwa komik merupakan satu bentuk seni populer terutama di kalangan anak-anak dan merupakan salah satu medium potensial untuk pendidikan sains dan komunikasi [5].

Berdasarkan uraian di atas, dilakukan penelitian terhadap dua kelas VIII di SMP AlAzhar Mandiri Palu. Pada penelitian tersebut, peneliti menyamakan model pembelajaran yang digunakan pada dua kelas yang diteliti, yaitu model pembelajaran guided discovery. Akan tetapi satu kelas diberikan perlakuan dengan menggunakan komik. Sehingga, melalui perlakuan ini, diharapkan dapat mengetahui perbedaan pemahaman konsep fisika antara kelas yang menggunakan model pembelajaran guided discovery berbantuan komik dengan kelas yang menggunakan model pembelajaran guided discovery tanpa bantuan komik pada siswa kelas VIII SMP Al-Azhar Mandiri Palu.

\section{METODOLOGI PENELITIAN}

Penelitian ini adalah penelitian Quasi Experimental yang menggunakan desain Nonequivalent Control Group. Bentuk desain ini dapat dilihat pada Tabel I.

TABEL 1 DESAIN PENELITIAN

\begin{tabular}{cccc}
\hline Kelompok & Pre-test & Perlakuan & Post-test \\
\hline Eksperimen & $\mathrm{O}_{1}$ & $\mathrm{X}$ & $\mathrm{O}_{2}$ \\
\hline Kontrol & $\mathrm{O}_{1}$ & - & $\mathrm{O}_{2}$ \\
\hline
\end{tabular}

Desain ini menggunakan kelas eksperimen sebagai kelas yang menggunakan model pembelajaran guided discovery berbantuan komik dan kelas kontrol yang menggunakan model pembelajaran guided discovery tanpa bantuan komik.

Peneliti mengambil seluruh siswa kelas VIII SMP Al-Azhar Mandiri Palu yang berjumlah 199 siswa sebagai populasi penelitian dengan pertimbangan bahwa pemahaman konsep fisika siswa yang masih berada dalam kategori sedang dan pada proses pembelajarannya, guru fisika di sekolah tersebut menggunakan model pembelajaran guided discovery, namun tidak pernah menggunakan komik. Hal tersebut sesuai dengan perlakuan yang dilakukan peneliti pada kelas kontrol yaitu penggunaan model guided discovery tanpa bantuan komik. Dari 199 siswa

divalidasi dengan menggunakan rumus korelasi product moment Pearson, kemudian dilakukan uji reliabilitas terhadap instrumen tersebut dengan menggunakan rumus alpha.

Data penelitian harus memenuhi syarat statistik parametrik, yaitu berdistribusi normal dan homogen sebelum dilakukan pengujian hipotesis. Uji normalitas data menggunakan uji Chi-Kuadrat. Selanjutnya, peningkatan yang dijadikan populasi, diambil dua kelas sebagai sampel penelitian, yaitu kelas VIII F (24 siswa) sebagai kelas eksperimen dan kelas VIII A (23 siswa) sebagai kelas kontrol. Teknik pengambilan sampel yaitu Purposive Sampling. Adapun pertimbangan yang digunakan dalam menentukan sampel yaitu kedua kelas diajarkan oleh guru yang sama dan berdasarkan penuturan guru tersebut kedua kelas ini memiliki pemahaman konsep yang sama.

Jenis data dalam penelitian ini adalah data kuantitatif yang bersumber pada sampel (sumber data primer) dengan pemberian tes awal (pre-test) dan tes akhir (post-test). Teknik pengumpulan data dalam penelitian menggunakan tes. Tes yang digunakan berbentuk uraian yang terdiri dari 5 nomor soal pemahaman konsep. Instrumen penelitian

pemahaman konsep siswa yang dikembangkan melalui model pembelajaran guided discovery berbantuan komik maupun model pembelajaran guided discovery tanpa bantuan komik dianalisis dengan menggunakan Gain Score (g).

\section{HASIL DAN PEMBAHASAN}

\section{Hasil Penelitian}


Penelitian ini bertujuan untuk mengetahui perbedaan pemahaman konsep fisika antara kelas yang menggunakan model pembelajaran guided discovery berbantuan komik dengan kelas yang menggunakan model pembelajaran guided discovery tanpa bantuan komik

Pre-test (tes awal) dan post-test (tes akhir) yang diberikan kepada siswa di kelas eksperimen dan kelas kontrol berupa soal pemahaman konsep berbentuk uraian yang berjumlah 5 nomor. Setiap nomor mewakili indikator pemahaman konsep, yaitu: menafsirkan, mencontohkan, mengklasifikasikan, membandingkan, dan menjelaskan. Pemberian pretest bertujuan untuk mengetahui pemahaman awal siswa terhadap konsep fisika sebelum diberikan perlakuan. Hal ini membantu peneliti untuk mengetahui poin yang akan menjadi penekanan saat mengajar.

Data hasil penelitian dengan memberikan pretest (tes awal) dan post-test (tes akhir) pada kelas eksperimen dan kelas kontrol disajikan pada Tabel 2.

TABEL 2 DESKRIPSI SKOR TES PEMAHAMAN KONSEP FISIKA UNTUK KELAS EKSPERIMEN DAN KELAS KONTROL

\begin{tabular}{ccccc}
\hline \multirow{2}{*}{ Uraian } & \multicolumn{2}{c}{ Pre-test } & \multicolumn{2}{c}{ Post-test } \\
\cline { 2 - 5 } & Ekspe-rimen & Kontrol & Ekspe-rimen & Kontrol \\
\hline Sampel $(\mathrm{n})$ & 24 & 23 & 24 & 23 \\
\hline Nilai Maksimum & 70 & 60 & 95 & 90 \\
\hline Nilai Minimum & 35 & 25 & 55 & 63,85 \\
\hline Skor Rata-rata & 56,75 & 40,28 & 19,29 & 13,08 \\
\hline Standar Deviasi & 9,19 & 9,10 & & 1121 \\
\hline
\end{tabular}

Gambaran awal pemahaman konsep siswa yang diperoleh peneliti melalui pemberian tes awal ini, yaitu siswa belum mampu menjelaskan konsep fisika yang berkaitan dengan materi Cahaya dan Alat Optik. Meskipun beberapa siswa sudah ada yang mampu memberikan jawaban yang tepat. Misalnya pada soal pre-test ada soal yang meminta siswa untuk menjelaskan alasan "mengapa koin yang diletakkan di dalam gelas berisi air terlihat lebih dekat ke permukaan". Beberapa siswa menjawab sebatas "karena adanya air" dan belum mampu memberikan penjelasan tentang penyebab hal itu terjadi. Atau hanya menjawab "karena terjadi pembiasan" dan belum mampu memberikan penjelasan yang lebih dalam mengenai hubungan konsep pembiasan dengan terlihatnya koin lebih dekat ke permukaan air.

Hasil analisis data berupa uji normalitas dengan menggunakan uji Chi-Kuadrat disajikan pada Tabel 3.

TABEL 3 HASIL UJI NORMALITAS DATA POST-TEST PADA KELASEKSPERIMEN DAN KELAS KONTROL

\begin{tabular}{ccc}
\hline Uraian & \multicolumn{2}{c}{ Post-test } \\
\cline { 2 - 3 } & Eksperimen & Kontrol \\
\hline Nilai $\chi_{\text {hitung }}^{2}$ & 4,88 & 2,46 \\
\hline Nilai $\chi_{\mathrm{t}(1-\alpha)(\mathrm{k}-3)}^{2}$ & 7,82 & 7,82 \\
\hline Keputusan & \multicolumn{3}{c}{ Berdistribusi normal } \\
\hline
\end{tabular}

Berdasarkan hasil uji normalitas data, diketahui bahwa nilai $\chi_{\text {hitung }}^{2}<\chi_{\mathrm{t}(1-\alpha)(\mathrm{k}-3)}^{2}$, untuk data post-test pada kelas eksperimen maupun pada kelas kontrol, maka dapat disimpulkan semua data berdistribusi normal.
Uji homogenitas dilakukan terhadap kelas eksperimen dan kelas kontrol pada data post-test. Hasil analisis uji homogenitas ditunjukkan pada Tabel 4

TABEL 4 HASIL UJI HOMOGENITAS DATA POST-TEST

\begin{tabular}{|c|c|}
\hline Uraian & Post-test \\
\hline$F_{\text {hitung }}$ & 1,36 \\
\hline$F_{\text {tabel }}($ probabilita $=0,05)$ & 4,06 \\
\hline Keputusan & Homogen \\
\hline $\begin{array}{l}\text { Berdasarkan hasil uji homogenitas tersebut } \\
\text { diketahui bahwa } F_{\text {hitung }}<F_{\text {tabel, sehingga dapat }} \\
\text { disimpulkan bahwa data yang diperoleh berasal } \\
\text { dari kelompok data yang homogen. Setelah }\end{array}$ & $\begin{array}{l}\text { syarat statistik parametrik terpenuhi, kemudian } \\
\text { dilakukan uji hipotesis menggunakan uji dua pihak. } \\
\text { Hasil perhitungan uji hipotesis ditunjukkan pada } \\
\text { Tabel 5. }\end{array}$ \\
\hline
\end{tabular}


Perbedaan Pemahaman Konsep Fisika Dasar pada Penerapan Model Pembelajaran Guided Discovery Berbantuan Komik dan Tanpa Bantuan Komik pada Siswa Kelas VIII SMP AI-Azhar Mandiri Palu (Sofwiyatul Banat)

TABEL 5 HASIL UJI HIPOTESIS DATA POST-TEST PADA KELAS EKSPERIMEN DAN KELAS KONTROL

\begin{tabular}{|c|c|c|c|c|c|}
\hline No & Kelas & $\begin{array}{l}\text { Skor Rata-rata } \\
(\bar{X})\end{array}$ & $t_{\text {hitung }}$ & $\begin{array}{c}\mathrm{t}_{(1-0,5 \alpha)} \\
(\alpha=0,05)\end{array}$ & Keputusan \\
\hline 1. & Eksperimen & 79,29 & 4,35 & 2,01 & $\mathrm{H}_{0}$ ditolak \\
\hline 2. & Kontrol & & \multicolumn{3}{|r|}{ c r } \\
\hline
\end{tabular}

Berdasarkan data Tabel 5 dan kriteria pengujian dimana $\mathrm{H}_{0}$ diterima jika $-\mathrm{t}_{(1-0,5 \alpha)}<$ $\mathrm{t}_{\text {hitung }}<\mathrm{t}_{(1-0,5 \alpha)}$ pada taraf signifikansi $\alpha=0,05$ dan $d k=\left(n_{A}+n_{B}\right)-2$ serta untuk harga t lainnya $\mathrm{H}_{0}$ ditolak, dapat diketahui bahwa nilai $t_{\text {hitung }}$ berada di luar daerah penerimaan $\mathrm{H}_{0}$. Dengan demikian $\mathrm{H}_{0}$ ditolak dan $\mathrm{H}_{1}$ diterima. Dengan kata lain, berdasarkan hasil uji hipotesis, diketahui bahwa terdapat perbedaan pemahaman konsep antara kelas yang menggunakan model pembelajaran guided discovery berbantuan komik dengan kelas yang menggunakan model pembelajaran guided discovery tanpa bantuan komik.

Hasil uji peningkatan hasil tes pada kelas eksperimen dan kelas kontrol disajikan dalam Tabel 6.

TABEL 6 HASIL UJI PENINGKATAN HASIL TES GAIN SCORE PADA KELAS EKSPERIMEN DAN KELAS KONTROL

\begin{tabular}{cccccc}
\hline \multirow{2}{*}{ No } & \multirow{2}{*}{ Kelas } & \multicolumn{2}{c}{ Persentase Rata-rata } & \multirow{2}{*}{ Gain Score $(\mathrm{g})$} & \multirow{2}{*}{ Kriteria Tingkat Gain } \\
\cline { 2 - 4 } & & Pre-test & Post-test & & \\
\hline 1. & Eksperimen & 56,94 & 77,08 & 0,47 & Sedang \\
\hline 2. & Kontrol & 43,84 & 64,86 & 0,37 & Sedang \\
\hline
\end{tabular}

Berdasarkan data pada Tabel 6 dapat diketahui bahwa Gain Score (g) siswa pada kelas yang mendapat perlakuan menggunakan model pembelajaran guided discovery berbantuan komik (kelas eksperimen) adalah 0,47 , sedangkan Gain Score kelas yang mendapat perlakuan menggunakan model pembelajaran guided discovery tanpa bantuan komik yaitu 0,37 . Gain score kedua kelas tersebut memenuhi kriteria $0,3 \leq \mathrm{g}<0,7$ yang berarti peningkatan pemahaman konsep siswa yang dikembangkan melalui model pembelajaran guided discovery berbantuan media komik maupun model pembelajaran guided discovery tanpa bantuan komik berada pada kriteria sedang.

\section{Pembahasan}

Berdasarkan hasil uji hipotesis, diketahui bahwa terdapat perbedaan pemahaman konsep antara kelas yang menggunakan model pembelajaran guided discovery berbantuan komik dengan kelas yang menggunakan model pembelajaran guided discovery tanpa bantuan komik.

Adapun faktor-faktor yang menyebabkan terdapat perbedaan pemahaman konsep antara kelas yang menggunakan model pembelajaran guided discovery berbantuan komik dengan kelas yang menggunakan model pembelajaran guided discovery tanpa bantuan komik adalah penggunaan komik fisika dalam pembelajaran.

Penggunaan komik inilah yang membedakan perlakuan antara kelas eksperimen dan kelas kontrol. Dalam pembelajaran di kelas eksperimen, komik berperan sebagai media yang digunakan dalam dua tahapan pada model pembelajaran guided discovery, yaitu tahap menyusun hipotesis dan tahap melakukan kegiatan penemuan. Sebelum merumuskan hipotesis, setiap siswa di kelas eksperimen diarahkan untuk membaca komik, misalnya pada materi yang berkaitan dengan pembiasan cahaya. Dari proses membaca komik tersebut, siswa mendapat informasi awal bahwa sendok di dalam air terihat seolah-olah patah karena adanya pembiasan yang disebabkan karena perubahan kecepatan cahaya. Jika dibandingkan jawaban dari kelompok siswa di kelas eksperimen dengan kelompok siswa di kelas kontrol, maka untuk siswa di kelas eksperimen ratarata menjawab dengan memberikan penjelasan yang lebih dalam (menjelaskan sebab pembiasan dapat terjadi), sedangkan untuk kelompok siswa di kelas kontrol, rata-rata menjawab "karena adanya air" atau sebatas "karena adanya pembiasan". Dengan melihat jawaban siswa di tahap ini, dapat diketahui bahwa dengan bantuan komik, proses memperoleh pemahaman konsep siswa semakin cepat terjadi. Dengan mengikuti alur cerita yang disajikan di komik ditambah dengan suguhan gambar-gambar menarik, siswa semakin mudah untuk memahami konsep fisika yang dipelajari. Tahap yang terdapat perbedaan perlakuan juga terjadi pada tahap melakukan kegiatan penemuan. Contohnya yaitu siswa dibimbing untuk mengamati apa yang terjadi ketika mereka memasukkan sendok ke dalam gelas berisi air, kemudian diarahkan untuk menjawab pertanyaan pada LKS (Lembar Kerja Siswa). Pada kelas eksperimen, siswa menggunakan media komik untuk membantu menjawab pertanyaan yang berkaitan dengan 
konsep pembiasan cahaya. Sedangkan untuk kelas kontrol tidak menggunakan komik. Dari jawaban siswa, diketahui bahwa, kedua kelas rata-rata menjawab dengan benar sekaligus mampu memberikan penjelasan yang mendalam. Guru cukup mengarahkan untuk membaca komik dan para siswa sudah dapat menemukan konsepnya, akan tetapi untuk kelas kontrol guru harus memberikan penjelasan yang lebih, sehingga siswa kurang terlibat dalam menemukan konsepnya.

Penggunaan komik dalam pembelajaran semakin memperjelas penyajian pesan dan informasi sehingga tidak terlalu bersifat verbalistis. Beberapa konsep fisika yang berkaitan dengan Cahaya dan Alat Optik diilustrasikan dengan baik dalam suguhan gambar dan cerita yang menarik serta mengandung humor sehingga tidak membosankan. Komik pada buku "WHY Cahaya dan Suara" bercerita tentang petualangan Komji dan Omji bersama 2 makhluk luar angkasa, Wooka dan Kheomong. Dalam petualangannya mencari harta karun di Planet Cahaya, keempat tokoh kartun tersebut harus menyelesaikan teka-teki yang berkaitan tentang konsep Cahaya dan Alat Optik dalam pembelajaran fisika. Ketika menyelesaikan teka-teki, tokoh kartun tersebut diceritakan menggunakan peralatan yang memang terdapat dalam kehidupan nyata dan biasa diperoleh siswa di kehidupan sehari-hari. Sehingga, cerita yang disajikan bersifat kontekstual, dan hal ini tentunya semakin memudahkan siswa untuk memahamai konsep yang dipelajari.

Komik yang digunakan berperan dalam mendukung tercapainya 5 indikator pemahaman konsep. Peranannya, yaitu: 1) Melalui membaca komik, siswa dapat menafsirkan (mengubah suatu bentuk gambaran menjadi bentuk lain). Contohnya, menafsirkan gambar tentang proses pembiasan cahaya dan gambar pembentukan sudut sinar datang dan sudut sinar pantul menjadi bentuk kata-kata. Komik memberikan penjelasan melalui percakapan antar tokohnya dan menggunakan bahasa yang mudah dipahami. 2) Melalui membaca komik, siswa dapat mengetahui contoh-contoh fenomena dari materi yang dipelajari. Sebab, komik mengilustrasikan langsung contoh tersebut melalui gambar. Dengan mendapat suatu contoh yang dapat dilihat secara langsung ilustrasinya, siswa mampu memberikan contoh lainnya. Misalnya, memberikan contoh dalam kehidupan yang membuktikan cahaya dapat merambat melalui ruang hampa. 3) Komik dapat membantu siswa dalam mengklasifikasikan (menentukan sesuatu dalam satu kategori). Misalnya, terdapat konsep tentang sudut sinar datang dan sudut sinar pantul. Komik menggambarkan pembentukan sudut sinar datang dan sudut sinar pantul kemudian menjelaskan definisi sudut sinar datang dan sudut dinar pantul dengan bahasa yang mudah dimengerti. Sehingga, ketika ditunjukkan gambar sudut sinar datang dan sudut sinar pantul, siswa dapat mengklasifikasikan sudut yang termasuk sudut sinar datang dan sudut sinar pantul. 4) Melalui membaca komik, siswa dapat membandingkan (menentukan hubungan antara dua ide obyek dan semacamnya). Untuk konsepkonsep yang hampir sama, siswa kesulitan dalam membedakannya. Komik mampu membedakan konsep tersebut dengan meyajikan gambar dan menggunakan bahasa yang mudah dimengerti. Contohnya adalah konsep mengenai sifat cermin cembung, cermin cekung, dan cermin datar. Komik yang digunakan mampu membedakan ketiga sifat cermin tersebut dan penggunaan ketiga cermin tersebut dalam kehidupan sesuai sifatnya. Penjelasannya diberikan dalam bentuk gambar dan melalui percakapan antar tokohnya. Sehingga, siswa dapat memperoleh kemampuan membandingkan dengan baik. 5) Melalui membaca komik, siswa dapat menjelaskan mengenai alasan suatu fenomena dapat terjadi, karena komik menjelaskan hal tersebut, tetapi tidak secara langsung, melainkan melalui adegan-adegan yang dilakukan tokohnya. Contohnya fenomena tentang koin yang dimasukkan ke dalam wadah berisi air akan terlihat dekat dengan permukaan air dibandingkan dengan koin yang dimasukkan dalam wadah yang tidak berisi air. Hal ini membuat siswa lebih memahami penjelasan dari suatu konsep.

Alur cerita pada komik yang digunakan sesuai dengan indikator pembelajaran yang ingin dicapai. Dimana setiap teka-teki yang harus diselesaikan oleh para tokoh dalam komik, mewakili indikator pembelajaran pada materi Cahaya dan Alat Optik. Penelitian ini juga menggunakan cuplikan adegan komik pada buku "Fisika Gasing (Fisika Gampang, Asik, dan Menyenangkan)" yang ditulis oleh Yohanes Surya, yang dimaksudkan untuk melengkapi konsep yang masih kurang dijelaskan pada komik di buku "WHY Cahaya dan Suara".

Meskipun terdapat perbedaan pemahamam konsep, apabila dilihat dari hasil analisa data, peningkatan hasil tes pada kelas eksperimen dan kelas kontrol, menyatakan bahwa Gain Score (g) siswa pada kelas yang mendapat perlakuan menggunakan model pembelajaran guided discovery berbantuan komik dengan Gain Score siswa pada kelas yang mendapat perlakuan menggunakan model pembelajaran guided discovery tanpa bantuan komik sama-sama berada pada kriteria sedang. Artinya, perbedaan pemahaman konsep antara kelas eksperimen dan kelas kontrol kurang signifikan. Hal ini disebabkan karena penerapan model pembelajaran guided discovery berbantuan komik yang membutuhkan waktu yang panjang tidak sebanding dengan waktu pembelajaran di kelas, dimana siswa hanya mendapat waktu yang sedikit untuk memahami cerita di komik. Sehingga penggunaan komik menjadi tidak efektif dalam pembelajaran di kelas. Hal ini telah diminimalisir oleh peneliti dengan cara 
Perbedaan Pemahaman Konsep Fisika Dasar pada Penerapan Model Pembelajaran Guided Discovery Berbantuan Komik dan Tanpa Bantuan Komik pada Siswa Kelas VIII SMP Al-Azhar Mandiri Palu

meminta siswa untuk membaca komik di rumah. Akan tetapi, hanya sekitar $5 \%$ siswa yang membaca.

Hasil penelitian ini, kurang sesuai dengan penelitian yang dilakukan oleh Pramadi, dkk yang menyatakan bahwa pembelajaran yang menggunakan komik berorientasi kearifan lokal Bali lebih cocok diterapkan dibandingkan dengan pembelajaran tanpa menggunakan komik berorientasi kearifan lokal Bali dalam pencapaian motivasi belajar dan pemahaman konsep [1].

\section{KESIMPULAN DAN SARAN}

\section{Kesimpulan}

Berdasarkan hasil analisis data dan pembahasan, maka dapat ditarik kesimpulan bahwa: terdapat perbedaan pemahaman konsep fisika yang kurang signifikan antara kelas yang menggunakan model pembelajaran guided discovery berbantuan komik dengan kelas yang menggunakan model pembelajaran guided discovery tanpa bantuan komik pada siswa kelas VIII SMP Al-Azhar Mandiri Palu.

\section{Saran}

Berdasarkan hasil penelitian, maka peneliti mengajukan saran untuk penelitian berikutnya, yaitu:

Pertama, agar pengontrolan terhadap kegiatan membaca komik lebih ditingkatkan lagi untuk memastikan bahwa seluruh siswa menggunakan komik dalam pembelajaran.

Kedua, disarankan agar sebelum melakukan pembelajaran, peneliti meminta siswa untuk mengungkapkan kembali konsep-konsep yang dipahami setelah membaca komik, guna mengetahui seberapa jauh siswa telah memahami cerita pada komik.

Ketiga, peneliti menyarankan menggunakan model pembelajaran lainnya yang dapat dikombinasikan dengan pembelajaran berbantuan komik.

\section{DAFTAR PUSTAKA}

[1] I.P.W.Y. Pramadi, I.W. Suastra, and I.M. Candiasa. "Pengaruh Penggunaan Komik Berorientasi Kearifan Lokal Bali terhadap Motivasi Belajar dan Pemahaman Konsep Fisika," Program Pascasarjana Universitas Pendidikan Ganesha Program Studi Pendidikan IPA, vol. 3, no. 1, pp. 1-10, 2013.

[2] D. Yurahly, "Perbedaan Hasil Belajar Fisika Model Pembelajaran Guided Discovery dan Direct Instruction Berbasis Keterampilan Proses Sains pada Siswa Kelas X SMP Negeri 4 Palu", Skripsi, Pendidikan Fisika, Universitas Tadulako, Palu, 2014.

[3] J. Suprihatiningrum, Strategi Pembelajaran: Teori dan Aplikasi. Yogyakarta: Ar-Ruzz Media, 2013.

[4] I. Sakti, Y.M. Puspasari, and E. Risdianto, "Pengaruh Model Pembalajaran Langsung (Direct Instruction) Melalui Media Animasi Berbasis Macromedia Flash terhadap Minat Belajar dan Pemahaman Konsep Fisika Siswa di SMP Plus Negeri 7 Kota Bengkulu," Jurnal Exacta, vol. 10, no. 1, pp. 1-10, 2012.

[5] M. Tatalovic, "Science Comics as Tools for Science Education and Communication: A Brief, Exploratory Study," Journal of Science Communication, vol. 8, no. 4, pp. 1-17, 2009. 